
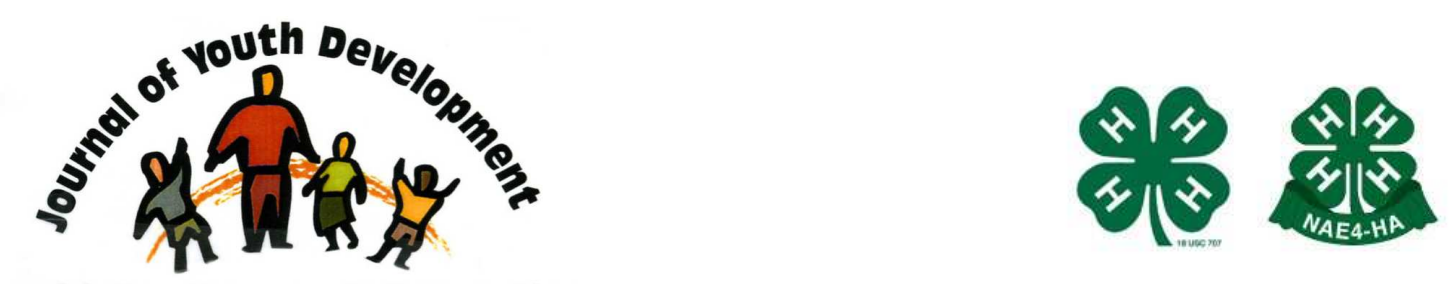

Bridging Research \& Practice

\title{
An Exploratory Study of the Five Cs Model of Positive Youth Development Among Indiana 4-H Youth
}

\author{
Abby M. Robinson \\ Orleans, IN \\ arobinson@frenchlick.com \\ Levon T. Esters \\ Youth Development and Agricultural Education \\ Purdue University \\ West Lafayette, IN \\ lesters@purdue.edu \\ Aryn Dotterer \\ Child Development and Family Studies \\ Purdue University \\ West Lafayette, IN \\ adottere@purdue.edu \\ Renee McKee \\ Youth Development and Agricultural Education \\ Purdue University \\ West Lafayette, IN \\ rmckee@purdue.edu

\section{Mark Tucker} \\ Youth Development and Agricultural Education \\ Purdue University \\ West Lafayette, IN \\ lesters@purdue.edu
}




\title{
JOURNAL OF YOUTH DEVELOPMENT \\ bridging research and practice

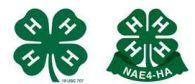

\section{An Exploratory Study of the Five Cs Model of Positive Youth Development Among Indiana 4-H Youth}

\author{
Abby Robinson \\ KidsFest Marketing Coordinator \\ Levon T. Esters, Aryn Dotterer, Renee McKee and Mark Tucker \\ Purdue University
}

\begin{abstract}
The purpose of this study was to explore the levels of positive youth development (PYD) among Indiana 4-H club participants. Questionnaires were collected from a convenience sample of [State] youth $(n=453)$. Findings indicated that youth who participated in the 4-H program reported significantly higher total positive youth development than those who had never participated in 4-H. Youth who participated in the 4-H program also reported significantly higher scores on four of the Five Cs of PYD (Confidence, Connection, Character, and Caring). The findings of this study contribute to the Developmental Systems Theory by confirming the role that 4-H has in contributing to positive youth development. Recommendations are provided to guide future research related to the Five Cs aspect of positive youth development among 4-H youth.
\end{abstract}

\section{Introduction}

The positive youth development perspective is becoming the primary framework for researchers and practitioners in youth development (Bowers et al., 2010, King, et al., 2005). The PYD perspective posits that every adolescent has strengths, or at least the capacity to develop strengths, that will enable youth to grow positively (Lerner, 2006). This approach also maintains that youth are completely capable of learning and developing skills, exploring the world that surrounds them, and then making contributions to that world (Lewis, 2008). Damon (2004) asserts that "the positive youth development approach aims at understanding, educating and engaging children in productive activities rather than at correcting, curing or treating them for maladaptive tendencies or so-called disabilities" (p. 15). This type of development is most often seen in environments that enable youth to see the importance of their position and their potential and "addresses the broader developmental needs of youth, in contrast to deficit- 
based models" (Rembert, 2009, as cited in Collins et al., 2008, p. 46). The features of PYD will emerge when the strengths of youth are aligned across adolescence with the resources available to them in their families, schools, and communities (Balsano, Phelps, Theokas, Lerner \& Lerner, 2009).

The 4-H Youth Development Program is one of many examples of youth programming that has implemented the PYD approach (Lewis, 2008). The mission of the 4-H Youth Development Program is to empower young people to reach their full potential by allowing them to work, as well as learn, alongside and with the help of caring adults. The 4-H Youth Development program provides many critical elements required of a program to encourage PYD including caring adults, a safe environment and opportunities to master skills and content (National 4-H Impact Assessment Project, 2001). 4-H programming functions through many different venues with 4-H clubs being the largest and most popular way youth take advantage of the many educational opportunities and activities 4-H offers.

Research shows that 4-H Youth Development programs have beneficial effects on youth by positively affecting development and therefore positively affecting their adulthood (Boyd, Herring, \& Briers, 1992). Though research continues to show that participating in constructive leisure activities, like 4-H, is a facilitating mechanism for positive development, more research is needed to strengthen this case (Morrissey \& Werner-Wilson, 2005). The case is often made that the relationship 4-H has with a land-grant university provides unique opportunities for youth that few other programs offer, however, in the push for accountability, providing evidence of the effectiveness of youth development programs such as 4-H is essential (Boyd et al., 1992).

\section{Purpose}

The purpose of this study was to explore the levels of positive youth development among [State] 4-H participants.

\section{Research Objectives}

The research objectives of this study were to:

1. Describe the levels of positive youth development (PYD) as measured by the Five Cs between 4-H and non-4-H participants.

2. Describe differences in positive youth development (PYD) as measured by the Five Cs across 4-H participation, gender and grade.

3. Describe the relationships between positive youth development (PYD) as measured by the Five $\mathrm{Cs}$ and $4-\mathrm{H}$ club and 4-H afterschool participation.

\section{Theoretical Framework}

Developmental Systems Theory (DST) is a contemporary human development theory and is particularly useful in studies of adolescent development (Kiely, 2010). The DST model (Figure 1) is composed of five primary components and include:

1) Ecological Risk/Protective factors,

2) Selection, Optimization, Compensation (SOC),

3) Positive Youth Development which is comprised of the Five Cs variables, 
4) Contribution, and

5) Risk/Problem Behaviors. For the purpose of this study, we focused on the 5 C's component of the DST model which has received the most attention within the PYD literature (Bowers et al., 2010). This is due to the substantially larger base of empirical evidence for the Five Cs in comparison to other components, the validity of the constructs, and the importance of the Five Cs variables in predicting both long- and short-term outcomes as demonstrated through longitudinal research (Heck \& Subramaniam, 2009).

Figure 1

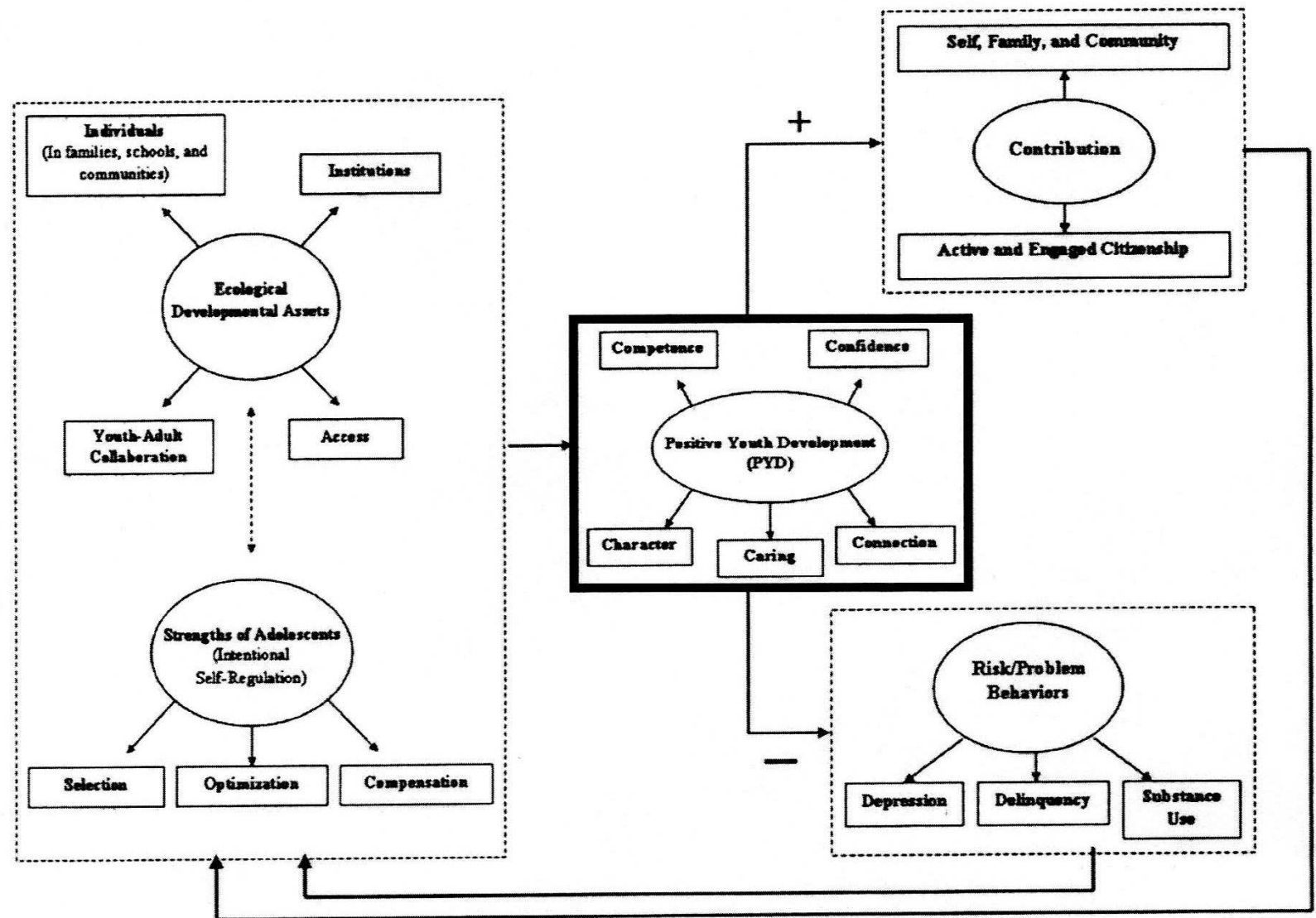

Figure 1. A Developmental Systems Theory-Based Framework of Thriving in Adolescence. Adapted from "Special issue introduction: The meaning and measurement of thriving: A view of the issues," by R.M. Lerner, A. von Eye, J.V. Lerner, S. Lewin-Bizan, and E.P. Bowers, 2010, Journal of Youth and Adolescence, 39, p. 712. Copyright 2010 by Springer Science+Business Media.

The 5 C's component introduces five key characteristics that are the building blocks of PYD. The Five Cs were developed based upon experience and reports of practitioners as well as a review of literature and include:
1) Competence,
2) Confidence,
3) Connection,
4) Character, and
5) Caring (Lerner, 2006; Bowers et al., 2010). 
Competence is defined as having a positive outlook on one's own actions in specific areas including social, cognitive, academic, and vocational realms (Phelps et al., 2009). Confidence refers to a young person who exhibits a largely positive sense of self-worth and who also exhibits self-efficacy (Phelps et al., 2009). Connection is manifested through constructive and encouraging relationships with people and institutions such as school, family, and peers. Character refers to a respect for rules, and a sense of right and wrong (Bowers et al., 2010). According to Phelps et al. (2009), Caring is defined as the embodiment of sympathy and empathy for other people. Youth are best able to become sympathetic and empathetic by interacting with adults who display these traits when helping those in need around them (Jones, 2005). It has been reported that youth exemplifying lower levels of the Five Cs face greater risk of experiencing personal, social and risk/behavioral problems (Lerner et al., 2008). These risk behaviors include depression, delinquency, and substance abuse (Lerner et al., 2010).

Recently, a greater focus has turned to the use of the Five Cs with research related to 4-H and PYD (Arnold, Dolenc, \& Rennekamp, 2009; Bossaer, 2009; Lerner \& Lerner, 2009). The 4-H Study of PYD is the first longitudinal study of positive youth development with Lerner, et al. (2008) being the first to develop measurements for positive youth development using the Five Cs framework. Findings from Lerner et al.'s (2008) annual report of Wave 4 indicated that 4-H participants were on higher trajectories for PYD and Contribution as well as lower trajectories and risky behaviors. 4-H youth were also more likely to make contributions to their communities than their non-4-H peers. Lerner et al. (2010) longitudinally compared a sample of 215 ninth grade 4-H participants and 215 ninth grade non-4-H participants from the 4-H Study of PYD Annual Report for Waves 1-5. Between these two groups, 4-H participants showed consistently higher scores for PYD, Contribution and SOC, and received lower scores on risk behaviors. Also, 4- $\mathrm{H}$ youth scored $25 \%$ higher in Contribution when compared to youth who were involved in other out-of-school activities, such as sports, arts or school clubs, and $41 \%$ lower on the risk/problem behavior measure than non-4-H youth. 4-H'ers were also shown to achieve higher grades, being more engaged with school and more often saw themselves going to college (Lerner \& Lerner, 2009). Finally, Bossaer (2009) compared 4-H participants with non 4-H participants according to their scores on Contribution. Bossaer found that active 4-H participants showed higher levels of community contribution than non-4-H participants. Not surprisingly, active 4-H participants reported significantly lower levels of risk behaviors than those youth who reported limited or no 4-H experience.

\section{Methods}

\section{Participants}

Two hundred fifty-five (56.9 \%) participants were female and $193(43.1 \%)$ were male. One hundred and sixty-one $(36.3 \%)$ youth were in $9^{\text {th }}$ grade, $129(29.1 \%)$ were in $10^{\text {th }}$ grade, 91 $(20.5 \%)$ were in $11^{\text {th }}$ grade and $63(14.2 \%)$ were in $12^{\text {th }}$ grade. Three hundred and ninetythree $(89.1 \%)$ of the participants were Caucasian. Remaining questionnaires were completed by youth who were multiethnic (5.7\%), Native American (2.5\%), African American (1.4\%), Hispanic (1.1\%). Participants were asked to indicate their age as of January 1, 2010, with the average age of participants being 15.5 years $(S D=1.21)$. Two hundred and thirty-two $(51.2 \%)$ participants were non-4-H participants and 221 (48.8\%) were 4-H participants.

\section{Measures}

The questionnaire used for this study was the short-form version of the original measure of the Positive Youth Development Student Questionnaire (Lerner et al., 2005). The questionnaire was designed to measure the Five Cs for use with youth who were over the age of 10 . Also, although each of the Five Cs is comprised of subscales, for the purpose of this study, only the 
scores for each of the Cs and Total PYD were used in the analysis. Items in the short-form version of the Positive Youth Development Student Questionnaire were adapted from five measures (Lerner et al., 2005). This included the: 1) Search Institute Profiles of Student LifeAttitudes and Behaviors, 2) Self- Perception Profile for Children (SPPC), 3) Teen Assessment Project (TAP) Survey Question Bank, and composite of items from 4) The Eisenberg Sympathy Scale, and 5) The Empathic Concern Subscale of the Interpersonal Reactivity Index (IRI). The Five Cs of PYD were measured by well-validated scales that were intended to measure important elements that would define each of the Five Cs (Gestsdottir, Lewin-Bizan, von Eye, Lerner, \& Lerner, 2009). Validity has been reported in numerous previously published articles (See Bowers, et al., 2010; Gestsdottir \& Lerner, 2007; Jelicic, et al., 2007; Lerner, et al. 2005). Post-hoc reliabilities for each of the Five Cs and total PYD were: Competence (.63), Confidence (.79), Connection (.90), Character (.86), Caring (.82), and Total PYD (.73).

Individual Five C scale scores were calculated and then averaged to reach an overall PYD score. Character was computed by calculating the mean score for each subscale individually then computing the means of the subscales. Competence scores were computed by calculating means for each subscale then averaging those scores with the score indicated for grades. For Caring, Connection and Confidence scores were calculated by simply averaging the scores. Items were all answered on a Likert-type scale of 0-3. The individual Five $\mathrm{C}$ scale scores are interpreted on a 100 point scale and computed by multiplying each scale score by 33.33.

The questionnaire also contained items eliciting various demographic data. Specifically, participants were asked to indicate their gender, grade, age, county of residence, race/ethnicity, type of 4-H involvement, 4-H club participation frequency, and the extent of participation in other out-of-school activities. 4-H participation (i.e., 4-H and non 4-H) was determined using two criteria. First, youth were asked whether or not they attended a 4-H camp. Youth who answered 'Yes' were identified as 4-H participants while youth who answered 'No' were identified as non-4-H participants. Second, youth were also asked to indicate their 4-H club and 4-H afterschool program participation by stating their level of involvement across various time frames: 1) Never, 2) Once a month or less, 3) A couple times a month, 4) Once a week, 5) A few times a week, or 6) Every day. Youth who indicated a specific time frame were categorized as 4-H participants while youth who answered 'Never' were categorized as non-4-H participants.

\section{Procedures}

This study used a descriptive survey design. The sample was comprised of a convenience sample of 4-H and non-4-H youth $(n=453)$. The Purdue University's Institutional Review Board approved the study protocol and all participants provided informed consent prior to participation in the study. Data were collected using a modified version of Dillman, Smyth, \& Christian's (2009) described implementation procedures. Specifically, we utilized 4-H Extension Educators from across Indiana as the primary contact to identify and invite youth to participate in our study rather than directly contacting the youth themselves. This procedure was employed because the researchers had greater access to 4-H Extension Educators and limited access to the youth participants' contact information (i.e., email and home mailing addresses). Also, using the 4-H Extension Educators proved to be the most practical way to reach youth because of the working relationships the Educators had with the schools in their counties. The steps that were used to contact the Educators and youth participants included: 1) Standard pre-notice letter to Educators, 2) Invitation letter including the URL link to the questionnaire to Educators and youth participants, 3) Thank you/reminder e-mail with the URL link to the questionnaire to Educators and youth participants, and 4) Reminder letter with the URL link to the questionnaire to Educators and youth participants. 
Initially, a pre-notice letter, published in Purdue University's county newsletter, informed all Extension Educators that an opportunity would be available to help gather data for a study that explored the levels of PYD of Indiana 4-H youth. Seven weeks later, Indiana's Assistant Director and Program Leader of 4-H Youth Development sent an e-mail again making Extension Educators across the state aware of the opportunity to participate in the study.

4-H Extension Educators from all 92 Indiana counties received a standard pre-notice letter from the researcher inviting them to consider participation in the study. The first official invitation letter was e-mailed to all Indiana 4-H Extension Educators, which also marked the first day of data collection. The e-mail was sent through an e-mail distribution list to Indiana Extension Educators who work in the 4- $\mathrm{H}$ Youth Development Program and contained detailed information on how the study would be conducted. This e-mail asked Educators to contact the researcher to indicate their interest in contacting youth who could participate in the study. Educators must have been willing to assist and follow the established protocol. Educators who responded indicating their participation were instructed to gather data by using one of the following options, or a combination of both:

1) Survey $9^{\text {th }}$ through $12^{\text {th }}$ grade students identified by a classroom teacher who had a prior collaborative programming relationship with the Extension Educator.

2) Survey 4-H members in grades 9 through 12 from the same county whose e-mail addresses the Educator had access to, or

3) The Educator could utilize both options above.

The URL link to the questionnaire included in the invitation letter for youth linked the participants directly to the questionnaire enabling youth to participate in the study from one of three locations: home, the Extension office, or a classroom. The data collection location was chosen by the Educator. In one instance, an Educator inquired whether or not distributing paper copies of the questionnaire in a classroom setting would be acceptable. This request was approved by the researcher and the researchers entered them into the database. The questionnaire included no identifiers. It was estimated that the questionnaire would take approximately 10 to 15 minutes to complete.

The first reminder e-mail was sent to Educators asking them to consider inviting the youth that they had access to participate in the study. According to Dillman, Smyth, \& Christian (2009), surveys being sent through the mail should be followed by a reminder postcard seven days after the questionnaire. The researcher drafted letters that were sent to the youth, but the Educators were responsible for ensuring that the letters were delivered to the participants. An Educator asked if mailing paper copies of the invitation to youth would be acceptable since they had access to more home mailing addresses than e-mail addresses. This request was also approved by the researchers.

A final e-mail reminder was sent asking Educators to consider assisting in the data collection effort, but at this point Educators could only e-mail invitations requesting youth participation. The data collection process resulted in $7054-\mathrm{H}$ and non-4-H participants from 33 counties being collected. However, once the data were examined for unusable questionnaires the final sample resulted in 453 useable questionnaires from 31 counties. The reason for the deletion of 252 cases was because of participants not completing the questionnaire thus rendering the questionnaires unusable. 


\section{Data Analysis}

Data were analyzed using descriptive statistics including means, standard deviations, frequencies and percentages. Independent samples t-tests were used to describe differences in positive youth development as measured by the Five $\mathrm{Cs}$ between $4-\mathrm{H}$ and non-4-H participants. A one-way Analysis of Variance was used to describe mean differences among the Five Cs and Total PYD across grade levels. Pearson's correlation coefficients were used to describe the relationships between positive youth development as measured by the Five Cs and selected demographic characteristics. Regarding the correlational analyses, we made one modification which included exploring relationships between the types of 4- $\mathrm{H}$ involvement (i.e., 4-H club participation and 4-H afterschool participation). This was done for the purpose of determining whether or not type of involvement is related to the $5 \mathrm{C}^{\prime}$. Effect sizes were calculated for relationships using Cohen's $r^{2}$ (1988) and relationship strength was described using Hopkin's (1997) conventions. Effect sizes for mean differences were calculated using Cohen's d (1988). Although it is not customary to use inferential statistics with a non-random sample, Uesseler, Ricketts, Duncan and Peake (2006) stated that inferential statistics are useful with data from a convenience sample if the sample is "carefully conceptualized to represent a particular population" (p. 104). As a result, findings from this study will add to the knowledge base by supplying preliminary data for comparison purposes, and "for providing the basis for future research from samples that would allow generalizability to larger populations," (Roberts, Harlin, \& Briers, 2007, p. 58).

\section{Findings}

\section{Objective 1: Describe the Levels of Positive Youth Development (PYD) as Measured} by the Five Cs Between 4-H and Non-4-H Participants

Levels of positive youth development for 4-H and non-4-H participants (See Table 1) were measured through the Five Cs by a 4-point Likert-type scale and are reported on a 100-point scale.

Mean scores for 4-H participants were Competence: 57.22, ( $S D=11.14)$, Confidence: 67.51 $(S D=16.37)$, Connection: 70.11, $(S D=16.16)$, Character: 73.4, $(S D=12.85)$, Caring: 75.52, $(S D=11.19)$, and Total PYD: 69.28, $(S D=10.17)$.

Scores for non-4-H participants were as follows: Competence: 55.77, ( $S D=12.17)$, Confidence: 61.48, $(S D=17)$, Connection: 65.39, $(S D=16.58)$, Character: 68.31, $(S D=15.14)$, Caring: 69.53, $(S D=19.15)$, and Total PYD: 64.42, $(S D=10.73)$. 
Table 1

Means and Standard Deviations for Five C's Between 4-H and Non-4-H Participants

\begin{tabular}{|l|c|c|c|c|}
\hline Five C's & \multicolumn{2}{|c|}{ 4-H Participants } & \multicolumn{2}{c|}{ Non 4-H Participants } \\
\hline & $M$ & $S D$ & $M$ & $S D$ \\
\hline Competence & 57.22 & 11.14 & 55.77 & 12.17 \\
\hline Confidence & 67.51 & 16.37 & 61.48 & 17.00 \\
\hline Connection & 70.11 & 16.16 & 65.39 & 16.58 \\
\hline Character & 73.4 & 12.85 & 68.31 & 15.14 \\
\hline Caring & 75.53 & 11.19 & 69.53 & 19.15 \\
\hline Total PYD & 69.28 & 10.17 & 64.45 & 10.73 \\
\hline
\end{tabular}

Note. Competence, Confidence, Connection, Character, Caring and Total PYD maximum score $=100$.

\section{Objective 2: Describe Differences in Positive Youth Development (PYD) as Measured by the Five Cs Across 4-H Participation, Gender and Grade}

Independent samples t-tests were used to assess differences in group means among 4-H and non-4-H participants for each of the Five Cs and Total PYD. Results are reported in Table 2. Significant differences were identified between 4-H and non-4-H participants on Confidence, Connection, Character, Caring and Total PYD. Only the Competence scale failed to yield significant differences between 4-H and non-4-H participants. Effect sizes for the mean differences between 4-H and non-4-H participants among the Five Cs scores and total PYD were small according to Cohen's (1988) criteria.

Table 2

T-test Results for Five C's Between 4-H and Non-4-H Participants

\begin{tabular}{|c|c|c|c|c|c|c|}
\hline $\mathbf{C}$ & 4-H Participation & $n$ & $M$ & SD & $t$ & $d$ \\
\hline \multirow[t]{2}{*}{ Competence } & $4-\mathrm{H}$ & 188 & 57.21 & 11.14 & -1.23 & .12 \\
\hline & Non 4-H & 203 & 55.77 & 12.17 & & \\
\hline \multirow[t]{2}{*}{ Confidence } & $4-\mathrm{H}$ & 193 & 67.51 & 16.37 & $-3.61 * *$ & .36 \\
\hline & Non 4-H & 208 & 61.49 & 17.00 & & \\
\hline \multirow[t]{2}{*}{ Connection } & $4-\mathrm{H}$ & 216 & 70.11 & 16.17 & $-3.04 * *$ & .29 \\
\hline & Non 4-H & 229 & 65.39 & 16.58 & & \\
\hline \multirow[t]{2}{*}{ Character } & $4-\mathrm{H}$ & 192 & 73.40 & 12.85 & $-3.61 * *$ & .36 \\
\hline & Non 4-H & 205 & 68.32 & 15.14 & & \\
\hline \multirow[t]{2}{*}{ Caring } & $4-\mathrm{H}$ & 218 & 75.53 & 17.19 & $-3.49 * *$ & .33 \\
\hline & Non 4-H & 230 & 69.52 & 19.15 & & \\
\hline \multirow[t]{2}{*}{ Total PYD } & $4-\mathrm{H}$ & 185 & 69.28 & 10.17 & $-4.51 * *$ & .46 \\
\hline & Non 4-H & 198 & 64.45 & 10.73 & & \\
\hline
\end{tabular}

Note. Total number of responses are unequal due to non-response within various categories. Competence, Confidence, Connection, Character, Caring and Total PYD maximum score $=100$. $* * p<.05$ 
Significant differences were identified between males and females on levels of Connection, Character, Caring and Total PYD (Table 3). Only the Competence and Confidence scales did not yield significant differences between males and females. Effect sizes for the mean differences between males and females among Competence, Confidence and Connection were small, moderate for Total PYD, and strong for Character and Caring according to Cohen's (1988) criteria.

Table 3

T-test Results for Five C's Between Males and Females

\begin{tabular}{|c|c|c|c|c|c|c|}
\hline C & 4-H Participation & $\boldsymbol{n}$ & $\boldsymbol{M}$ & $\boldsymbol{S D}$ & $\boldsymbol{t}$ & $\boldsymbol{d}$ \\
\hline Competence & Males & 164 & 56.27 & 11.25 & -.279 & .03 \\
\cline { 2 - 7 } & Females & 227 & 56.61 & 12.03 & & \\
\hline Confidence & Males & 169 & 63.16 & 15.95 & -1.23 & .13 \\
\cline { 2 - 7 } & Females & 232 & 65.28 & 17.62 & & \\
\hline \multirow{3}{*}{ Connaracter } & Males & 188 & 64.84 & 16.06 & $-3.04^{* *}$ & .29 \\
\cline { 2 - 7 } & Females & 253 & 69.62 & 16.61 & & \\
\hline \multirow{2}{*}{ Caring } & Males & 167 & 63.93 & 15.35 & $-8.46^{* *}$ & .91 \\
\cline { 2 - 7 } & Females & 230 & 75.74 & 11.10 & & \\
\hline \multirow{2}{*}{ Total PYD } & Males & 189 & 63.62 & 18.90 & $-9.04^{* *}$ & .90 \\
\cline { 2 - 7 } & Females & 255 & 78.74 & 15.24 & & \\
\cline { 2 - 7 } & Males & 158 & 62.77 & 10.66 & $-6.46^{* *}$ & .67 \\
\hline
\end{tabular}

Note. Total number of responses are unequal due to non-response within various categories. Competence, Confidence, Connection, Character, Caring and Total PYD maximum score $=100$. $* * p<.01$

A one way analysis of variance test (ANOVA) was conducted to determine whether means for the Five Cs and for Total PYD varied among the four grade levels. Results shown in Table 4 revealed that means varied at statistical significance across the various grade levels for two of the Five Cs, Confidence and Caring, as well as for Total PYD (Confidence: $A(3,391)=2.92, p<$ $.05, n^{2=} .022$; Caring, $f(3,436)=2.90, p<.05, n^{2}=.02$; Total PYD, $(3,377)=2.92, p<.05$, $\left.n^{2}=.023\right)$.

Post-hoc comparisons using Bonferroni comparisons showed that the mean Confidence levels for $9^{\text {th }}$ grade students $(M=62.07)$ was significantly lower than the mean for $12^{\text {th }}$ grade students $(M=70.15)$. Relative to Caring, post-hoc comparisons showed that the mean levels for $9^{\text {th }}$ grade students $(M=69.22)$ was significantly lower than the mean for $10^{\text {th }}$ grade students $(M=75.40)$. Post-hoc testing failed to show any statistically significant differences for Total PYD by grade level, despitea significant $F$ statistic. The significant difference in group means may have resulted from the larger number of responses in the overall dataset used to generate the $F$ statistic. Smaller numbers of responses are used in Post-hoc testing. 
Table 4

Analysis of Variance Results for the Five Cs and Total PYD

\begin{tabular}{|c|c|c|c|c|c|}
\hline Variable & $M$ & SD & $\boldsymbol{F}$ & $P$ & $n^{2}$ \\
\hline Competence & & & .022 & .996 & .00 \\
\hline Grade 9 & 56.59 & 11.86 & & & \\
\hline Grade 10 & 56.50 & 11.76 & & & \\
\hline Grade 11 & 56.26 & 11.25 & & & \\
\hline Grade 12 & 56.76 & 11.49 & & & \\
\hline Confidence & & & 2.92 & $.034 *$ & .02 \\
\hline Grade 9 & 62.07 & 17.68 & & & \\
\hline Grade 10 & 64.56 & 17.26 & & & \\
\hline Grade 11 & 64.27 & 16.46 & & & \\
\hline Grade 12 & 70.15 & 14.74 & & & \\
\hline Connection & & & 2.24 & .083 & .02 \\
\hline Grade 9 & 64.93 & 17.70 & & & \\
\hline Grade 10 & 69.75 & 15.41 & & & \\
\hline Grade 11 & 68.16 & 17.48 & & & \\
\hline Grade 12 & 68.72 & 13.68 & & & \\
\hline Character & & & .658 & .578 & .01 \\
\hline Grade 9 & 69.57 & 14.48 & & & \\
\hline Grade 10 & 71.87 & 14.11 & & & \\
\hline Grade 11 & 70.32 & 14.41 & & & \\
\hline Grade 12 & 70.72 & 14.43 & & & \\
\hline Caring & & & 2.9 & $.035 *$ & .02 \\
\hline Grade 9 & 69.22 & 19.79 & & & \\
\hline Grade 10 & 75.40 & 18.00 & & & \\
\hline Grade 11 & 73.54 & 15.87 & & & \\
\hline Grade 12 & 72.81 & 17.58 & & & \\
\hline Total PYD & & & 2.92 & $.034 *$ & .02 \\
\hline Grade 9 & 64.65 & 11.43 & & & \\
\hline Grade 10 & 68.16 & 10.04 & & & \\
\hline Grade 11 & 67.08 & 10.81 & & & \\
\hline Grade 12 & 68.60 & 9.97 & & & \\
\hline
\end{tabular}

Note. Competence, Confidence, Connection, Character, Caring and Total PYD maximum score $=100$.

$* \mathrm{p}<.05$ 
Objective 3: Describe the Relationships Between PYD as Measured by the Five Cs and 4-H Club and 4-H Afterschool Participation

Pearson's correlations were used to describe the relationships between Total PYD, each of the Five Cs, 4-H Club participation and 4-H afterschool participation (Table 5). Hopkin's (1997) and Cohen's (1988) conventions were used to describe strength and effect sizes of the relationships. An effect size, or an $r^{2}$, that is less than .08 is considered small, an $r^{2}$ falling between .09 and .24 is considered medium and any $r^{2}$ greater than .25 is considered large. All significant relationships ranged from low to high $(.12-.74)$.

\section{Table 5}

Pearson's Correlations Among the Five Cs, PYD, 4-H Club Participation and 4-H Afterschool Participation

\begin{tabular}{|l|c|c|c|c|c|c|c|c|}
\hline Variable & $\mathbf{1}$ & $\mathbf{2}$ & $\mathbf{3}$ & $\mathbf{4}$ & $\mathbf{5}$ & $\mathbf{6}$ & $\mathbf{7}$ & $\mathbf{8}$ \\
\hline 1. Total Confidence & ----- & & & & & & & \\
\hline 2. Total Competence & $.44^{* *}$ & ----- & & & & & & \\
\hline 3. Total Connection & $.48^{* *}$ & $.23^{* *}$ & ----- & & & & & \\
\hline 4. Total Character & $.30^{* *}$ & $.17^{* *}$ & $.51^{* *}$ & ----- & & & & \\
\hline 5. Total Caring & $.18^{* *}$ & $.13^{* *}$ & $.46^{* *}$ & $.64^{* *}$ & ----- & & & \\
\hline 6. Total PYD & $.69^{* *}$ & $.52^{* *}$ & $.78^{* *}$ & $.74^{* *}$ & $.72^{* *}$ & ----- & & \\
\hline 7. 4-H Club Participation & $.15^{* *}$ & .04 & $.12^{*}$ & $.14^{* *}$ & $.15^{* *}$ & $.19^{* *}$ & ----- & \\
\hline 8. 4-H Afterschool Participation & .07 & -.03 & .05 & .08 & .06 & .09 & $.64^{* *}$ & ----- \\
\hline
\end{tabular}

Note. Total number of responses are unequal due to non-response within various categories.

$* p<.05, * * p<.01$

\section{Conclusions}

Youth who participated in the 4-H program reported higher levels of total positive youth development than those who had never participated in 4-H. These findings are important because the outcomes of positive youth development include lower participation in risky behaviors, greater community involvement, increased civic engagement, higher grades in school, and aspirations to pursue post-secondary education (Lerner \& Lerner, 2009). However, although the findings of the study align with findings from Lerner et al. (2009) and Lerner et al. (2008) who also found that 4-H youth reported higher levels of positive youth development the "true value of 4-H programs comes not from short-term results or even the effects over a few years... but from the programs' influence on lifelong pathways of development" (Lerner, Lerner \& Phelps, 2009, p. 16).

Youth who participated in the 4-H program reported significantly higher scores on four of the Five Cs (Confidence, Connection, Character, and Caring). Among these Cs, 4-H participants averaged 2.3 to 7.5 points higher than non-4-H participants. This finding is unique because prior studies (see Lerner et al., 2009; Lerner, Lerner, \& Phelps, 2008) have only discussed the concept of PYD as a function of the Five Cs. It should be noted that reporting findings related to the Five Cs individually is contrary to previous research using Developmental Systems Theory. For example, Lerner noted that each " $C$ " is measured by its own individual scale. As such, PYD is typically only reported as a collective construct of the Five Cs (J. Lerner, personal 
communication, February 13, 2011). However, in this study the researchers was primarily interested in exploring differences in levels of PYD between 4-H and non-4-H participants; as such differences in individual $\mathrm{C}$ scores were deemed important and were thus reported.

Although effect sizes between mean differences were small according to Cohen (1988), this may result from the population being very similar due to the convenience sampling methods used in the study. In this study, the researcher did not contact the participants, rather; the Educator was responsible for recruiting the participants. Small effect sizes could also be a result of the researcher's inability to assess the intensity (i.e., depth and breadth) of the participants' involvement in 4-H programming and other out-of-school programs. Both $4-\mathrm{H}$ and non-4-H participants in this study reported involvement in other out- of-school activities such as Boy Scouts, the YWCA, and the Big Brothers Big Sisters program. Lerner (2005) and Busseri and Rose-Krasnor (2007) also found that youth are typically involved in more than one youth development program. Although Theokas et al., (2006) reported that participation in more than one out-of-school time program is common and beneficial for youth, they also note that this makes it increasingly difficult for researchers to pin-point which program had the greatest impact on the development of a young person.

Females also reported significantly higher levels of Connection, Character, Caring and Total PYD than males. These findings align with findings from previous research indicating that females achieved higher PYD than their male counterparts (Lerner, 2005b; Jelicic et al., 2007; Zimmerman, 2007). However, this study measured PYD overall rather than through specific domains such as math, sports, or language arts as was done in previous studies.

Finally, findings indicated that there were significant differences across grades in levels of Confidence, Caring and Total PYD. Confidence was significantly different between youth in $9^{\text {th }}$ and $12^{\text {th }}$ grades with $12^{\text {th }}$ grade students reporting an average of 8.1 points higher. Caring was significantly different between youth in $9^{\text {th }}$ and $10^{\text {th }}$ grades with $10^{\text {th }}$ grade students reporting an average of 6.2 points higher. Total PYD was significantly different; however, specific grade level differences were not detected. Despite the findings of increased PYD across grade levels, it is difficult to compare this study's findings to previous research because of conflicting results in addition to previous research being based on longitudinal data whereas this study utilized a cross-sectional design.

Findings from this study revealed significant relationships between 4- $\mathrm{H}$ club and 4-H afterschool participation and four of the Five Cs (Confidence, Character, Caring, and Connection) as well as between 4-H participation and total PYD. Lerner, Lerner, and Phelps (2008) reported that 4-H participation leads to higher levels of PYD and a stronger connection between 4-H participation and PYD scores. Findings from this study also support Lerner et al. (2010) who found that 4-H club and 4-H afterschool participation was consistently related to higher levels of PYD. Findings revealing significant relationships between levels of $4-\mathrm{H}$ participation and four of the Five Cs seem reasonable considering that PYD is a function of the individual Five Cs (J. Lerner, personal communication, February 13, 2011).

\section{Limitations}

A number of limitations should be considered when interpreting the findings of this study. First the findings of this study are limited to the state of Indiana thus the findings cannot be generalized to other states. The data collection method of this study did not include a randomized selection of the participants and is not generalizable 
beyond the participants studied. Also, the researchers cannot control for the effects of participants being involved in other youth programs which may have influenced their survey responses. Finally, self-report is a limitation in this study because the accuracy of this data is reliant upon the honesty and accuracy of the participants' opinions of themselves.

\section{Implications for Practice}

Findings from this study serve as information to help promote and accomplish the goals of the Indiana 4-H youth development program. In particular, based on the findings of this study it is reasonable to assume that 4-H Youth Development programs in Indiana make a difference in the lives of young people in terms of enhancing their positive youth development. However, it is also understood that the positive youth development reported by an individual cannot be attributed to 4-H alone nor to any single out-of-school activity (Theokas, Lerner, Phelps, and Lerner, 2006). Yet still, this study in concert with previous research indicates that youth who participate in 4-H youth development programming report higher levels of positive youth development. Thus, despite the fact that no causal inferences can be made based on the research design used in this study, there is reason to speculate that the Indiana 4-H program is providing opportunities for youth to become engaged in youth development activities and experiences which lead to positive youth outcomes.

\section{Recommendations for Future Research}

Youth can participate in 4-H programming a number of different ways including 4-H clubs, 4-H camps and 4-H afterschool activities. However, because involvement in 4-H usually occurs on average once or twice a month, asking youth if they were involved in 4- $\mathrm{H}$ a couple times per week or every day, as was done in this study, proved to be somewhat limiting. Also, 4-H experiences can vary greatly depending on a particular city or state. As such, future research should try to ascertain a more accurate measure of the duration (years involved in the 4- $\mathrm{H}$ program) and frequency (how often youth participate) of 4-H participation. Perhaps the most important approach to measuring the 4-H experience is through intensity (depth and breadth) which could be assessed by asking questions regarding meeting attendance and leadership, as well as involvement in other 4-H programs like Junior Leaders or Master Gardeners.

Clearly defining 4-H experiences would allow researchers to more precisely measure the effect 4-H participation has on young people. Because the data for this study was collected using a convenience sample; future studies would be strengthened by gathering data from a random sample thus enhancing external validity. The homogeneous sample of the study also limits generalizability to other racial and ethnic groups. Thus, future research would benefit from collecting data involving a more diverse sample among both 4-H and non-4-H participants. Finally, the short version of the PYD questionnaire used in this study did not include items measuring the Contribution or risk/problem behaviors that are recognized as key components of Developmental Systems Theory. To better contribute to theory, future research should include items that assess these two constructs which will then lend to findings and conclusions that can be better linked to DST. 


\section{References}

Arnold, M.E., Dolenc, B.J., \& Rennekamp, R.A. (2009). An assessment of 4-H volunteer experiences: Implications for building positive youth development capacity. Journal of Extension, 47(5). Retrieved from http://www.joe.org/joe/2009october/a7.php.

Balsano, A.B., Phelps, E., Theokas, C., Lerner, J.V., \& Lerner, R.M. (2009). Patterns of early adolescents' participation in youth developing programs having positive youth development. Journal of Research on Adolescence, 19(2), 245-295. doi: 10.1111/j.1532-7795.2009.00595.x.

Bossaer, L. (2009). Assessment of Indiana 4-H youth and their community contribution: Indiana 4-H study of positive youth development. Retrieved from Dissertations \& Theses. (AAT 1469817).

Bowers, E.P., Li, Y., Kiely, M.K., Brittian, A., Lerner, J.V., \& Lerner, R.M. (2010). The Five Cs model of positive youth development: A longitudinal analysis of confirmatory factor structure and measurement invariance. Journal of Youth and Adolescence, 39, 720-735. doi: 10.1007/s10964-010-9530-9.

Boyd, B.L., Herring, D.R., \& Briers, G.E. (1992). Developing life skills in youth. Journal of Extension, 30(4).Retrieved from http://www.joe.org/joe/1992winter/a4.php.

Busseri, M.A., \& Rose-Krasnor, L. (2007). Breadth and intensity: Salient, separable, and developmentally significant dimensions of structured youth activity involvement. The British Psychological Society 27, 907-933. doi:10.1348/026151008X397017.

Cohen, J. (1988). Statistical Power Analysis for the Behavioral Sciences (2nd ed.). New Jersey: Lawrence Erlbaum.

Collins, M.E., Hill, N., \& Miranda, C. (2008). Establishing positive youth development approaches in group home settings: Training implementation and evaluation. Child and Adolescent Social Work Journal, 25, 43-54. doi:10.1007s/10560-008-0111-7.

Damon, W. (2004). What is positive youth development? The Annals of the American Academy of Political and Social Science, 591, 13-24. doi:10.1177/0002716203260092.

Dillman, D.A., Smyth, J.D., \& Christian, L.M. (2009). Internet, mail and mixed- mode surveys: The tailored design method. Hoboken, NJ: John Wiley \& Sons, Inc.

Gestsdottir, S., \& Lerner, R.M. (2007). Intentional self-regulation and positive youth development in early adolescence: Findings from the 4-H study of positive youth development. Journal of Developmental Psychology, 43(2), 508-521. doi:10.1037/0012-1649.43.2.508.

Gestsdottir, S., Lewin-Bizan, S., von Eye, A., Lerner, J.V., \& Lerner, R.M. (2009).

The structure and function of selection, optimization and compensation in middle adolescence: Theoretical and applied implications. The Journal of Applied Developmental Psychology, 30, 585-600. doi:10.1016/j.appdev.2009.07.001

Heck, K.E. \& Subramaniam, A. (2009). Youth development frameworks. [Monograph]. Retrieved from http://www.ca4h.org/files/1224.pdf. 
Hopkins, W.G. (1997). A new view of statistics. Internet Society for Sport. Science. Retrieved from http://www.sportsci.org/resource/stats/.

Jelicic, H., Bobek, D.L., Phelps, E., Lerner, R.M., \& Lerner, J.V. (2007). Using positive youth development to predict contribution and risk behaviors in early adolescence: Findings from the first two waves of the 4-H study of positive youth development. International Journal of Behavioral Development, 31(3), 263-273. doi: 10.1177/0165025407076439.

Jones, K.R. (2005). Positive youth development and 4-H: Making the connection. Cooperative Extension Service, publication No. 4MO-200. Lexington KY: University of Kentucky.

Kiely, M. (2010). Intentional self-regulation and participation in 4-H programs: Individual and contextual bases of positive youth development and contribution. Retrieved from ProQuest Digital Dissertation. (AAT 1476059).

King, P.E., Dowling, E.M., Mueller, R.A., White, K., Schultz, W., Osborn, P., et al. (2005). Thriving in adolescence: The voices of youth- serving practitioners, parents and early and late adolescents. The Journal of Early Adolescence, 25(1), 94-112. doi: 10.1177/0272431604272459

Lerner, R.M. (2005a). Promoting positive youth development: Theoretical and empirical bases. Washington, DC: National Academies of Science.

Lerner, R.M. (2005b). Theoretical frames for understanding and enhancing adolescent development. [PowerPoint slides]. Retrieved from_http://www.bocyf.org/ lerner presentation.pdf

Lerner, R.M. (2006). Resilience as an attribute of the developmental system: Comments on the papers of professors Masten \& Wachs. Annals of the New York Academy of Sciences, 1094(1), 40-51. doi: 10.1196/annals.1376.005.

Lerner, R.M., \& Lerner, J.V. (2009). Waves of the future: Report of the findings from the first six years of the 4-H Study of Positive Youth Development. Medford, MA: Institute for Applied Research in Youth Development, Tufts University.

Lerner, R.M., Lerner J.V., \& Phelps E. (2008). The positive development of youth: Report of the findings from the first four years of the $4-\mathrm{H}$ study of positive youth development. Medford, MA: Tufts University Office of Publications.

Lerner, R.M., Lerner, J.V., \& Phelps, E. (2009). Waves of the future: The first five years of the 4-H study of positive youth development. College Station, TX: AgriLife Communications.

Lerner, R.M., Lerner, J.V., Almerigi, J.B., Theokas, C., Phelps, E., Gestsdottir, S., von Eye, A., (2005). Positive youth development, participation in community youth development programs, and community contributions of fifth-grade adolescents: Findings from the first wave of the 4-H study of positive youth development. Journal of Early Adolescence, 25(1), 17-71.

doi: $10.1177 / 0272431604272461$ 
Lerner, R.M., von Eye, A., Lerner, J.V., Lewin-Bizan, S., \& Bowers, E.P. (2010). Special issue introduction: The meaning and measurement of thriving: A view of the issues. Journal of Youth and Adolescence 39,707-719. doi:10.007/s10964-010-9531-8

Lewis, D. (2008). Ohio public school students' out-of-school time study: Measuring the impact of Ohio's 4-H youth development community club program. Retrieved from Dissertations \& Theses. (AAT 3321367).

Morrissey, K.M., \& Werner-Wilson, R.J. (2005).The relationship between out-of- school activities and positive youth development: An investigation of the influences of communities and family. Adolescence, 40(157), 67-85. Retrieved from: http://florida4h.org/news/public relations/files/Out of school activities.pdf

National 4-H Impact Assessment Project. (2001). Prepared and engaged youth. Washington, DC: United States Department of Agriculture. Available from National 4-H Headquarters website, http://www.national4- hheadquarters.gov/about/4h_impact.htm.

Phelps, E., Zimmerman, S., Warren, A.E.A., Jelicic, H., von Eye, A., \& Lerner, R.M. (2009). The structure and developmental course of positive youth development (PYD) in early adolescent: Implications for theory and practice. Journal of Applied Developmental Psychology, 30, 571-584. doi:10.1016/j.appdev.2009.06.003.

Rembert, K. (2009). Perceptions of county extension 4-H agents/educators regarding essential elements and delivery modes of positive youth development and their collective impact on character. Retrieved from Dissertations \& Theses. (AAT 3369278).

Roberts, T.G., Harlin, J.F., \& Briers, G.E. (2007). The relationship between teaching efficacy and personality type of cooperating teachers. Journal of Agricultural Education, 48, 55-66.

Theokas, C., Lerner, J.V., Phelps, E., \& Lerner, R.M. (2006). Cacophony and change in youth after school activities: Findings from the 4-H study of positive youth development. Journal of Youth Development 1(1). Retrieved from http://www.uwex.edu/ces/4h/ educators/documents/Theokasetal.JYD12006.pdf40408d2250c\%40sessionmgr12

Uesseler, J., Ricketts, J.C., Duncan D.W., \& Peake, J.B. (2006). In-service delivery: Method preferred by Georgia agriculture teachers. Journal of Southern Agricultural Education Research, 56(1), 101-113. Retrieved from http://pubs.aged.tamu.edu/ jsaer/Vol56Whole.pdf\#page=101

Zimmerman, S.M. (2007). Intentional self-regulation in early adolescence: Assessing the structure of selection, optimization, and compensation processes. Retrieved from Dissertations \& Theses. (AAT 1442560).

(C) Copyright of Journal of Youth Development $\sim$ Bridging Research and Practice. Content may not be copied or emailed to multiple sites or posted to a listserv without copyright holder's express written permission. However, users may print, download or email articles for individual use. 